\title{
Simulation of dynamic recrystallization of a magnesium alloy with a cellular automaton method coupled with adaptive activation energy and matrix deformation topology
}

\author{
Sibing Wang, Wenchen Xu*, He Wu, Ranxu Yuan, Xueze Jin, and Debin Shan \\ School of Materials Science and Engineering \& National Key Laboratory for Precision Hot Processing of Metals, Harbin Institute \\ of Technology, Harbin 150001, China
}

Received: 11 December 2020 / Accepted: 1 March 2021

\begin{abstract}
The cellular automata (CA) model combining topological deformation and adaptive activation energy was successfully constructed to analyze the thermal dynamic recrystallization of the magnesium alloy (AZ61). The simulation datum shown that the recrystallization nucleation located on the grain boundary (GB) once the density of dislocation accumulated to specific value, and the result presents a typical characteristics i.e., repeated nucleation and growth. The simulation results agree well with the experimental results because the activation energy affects recrystallization by affecting nucleation rate.
\end{abstract}

Keywords: AZ61 magnesium alloy / cellular automaton / adaptive activation energy / deformation topology / dynamic growth criterion

\section{Introduction}

With increased demands for reducing structure weight as well as reducing energy consumption in aviation and automobile industries, magnesium $(\mathrm{Mg})$ alloys are attracting increased attention due to their excellent properties such as lightweight and high specific strength [1-4]. While these structural components are achieved largely through using forming processes, study of $\mathrm{Mg}$ alloys thermal deformation behavior and microstructure evolution is a prerequisite for ensuring to produce high-performance workpieces of $\mathrm{Mg}$ alloys.

Bajargan et al. [5] and $\mathrm{Xu}$ et al. [6] studied The hot deformation behavior of AZ31/AZ61 Mg alloy, respectively. Recently, Kugler and Turk [7] established the recrystallization kinetics model of isothermal compression, and analyzed the relationship between the average grain size and dynamic recrystallization (DRX) process. Zhang et al. [8], Guo and Ding [9] and Turk and Kugler [10] studied the DRX process by two-dimensional CA model.

In the research reported in this paper, the focus was on the coupling effects of adaptive activation energy and matrix deformation topology on the DRX behavior of magnesium alloys.

\footnotetext{
* e-mail: xuwc_76@hit.edu.cn; shandebin@hit.edu.cn
}

\section{Materials and methods}

The experimental material for hot compression is commercial $\mathrm{Mg}$ alloy hot extruded bars (diameter $10 \mathrm{~mm}$, length $500 \mathrm{~mm}$ ) with nominal composition $\mathrm{Mg}-5.7 \mathrm{Al}-0.9 \mathrm{Zn}-0.5 \mathrm{Mn}$ (wt\%). Before hot compression, the extruded-rods were heated to $400{ }^{\circ} \mathrm{C}$ and held for $4 \mathrm{~h}$ to obtain homogeneous microstructure (air cooling). The radius/height of the hot compression samples was $4 / 12 \mathrm{~mm}$. All the tests of isothermal compression were performed on the thermal simulation testing machine (type: Gleeble-1500D). The range of temperature, strain rate and height reduction was $350-450{ }^{\circ} \mathrm{C}, 0.001-1 \mathrm{~s}^{-1}$ and $0-50 \%$, respectively. The compression procedure is shown in Figure 1. In order to improve the temperature uniformity, the samples were held for 3 minutes before compression.

Each sample was cut along the axial section of the quenched specimens, and then mechanically polished and chemically etched for microstructure analysis. The etchant consisted of picric and acetic acid $(27.5 \mathrm{~g}$ and $25 \mathrm{ml})$, distilled water and alcohol ( 50 and $450 \mathrm{ml}$ ). Microstructure results were detected by Olympus-GX71 optical microscope (OM) and Talos F200X transmission electron microscope (TEM). Mean grain size of initial hot compression specimens was $44.6 \mu \mathrm{m}$ measured by quantitative metallographic method. The specific locations of microstructure simulations and experimental observations are in the central part of the samples. 


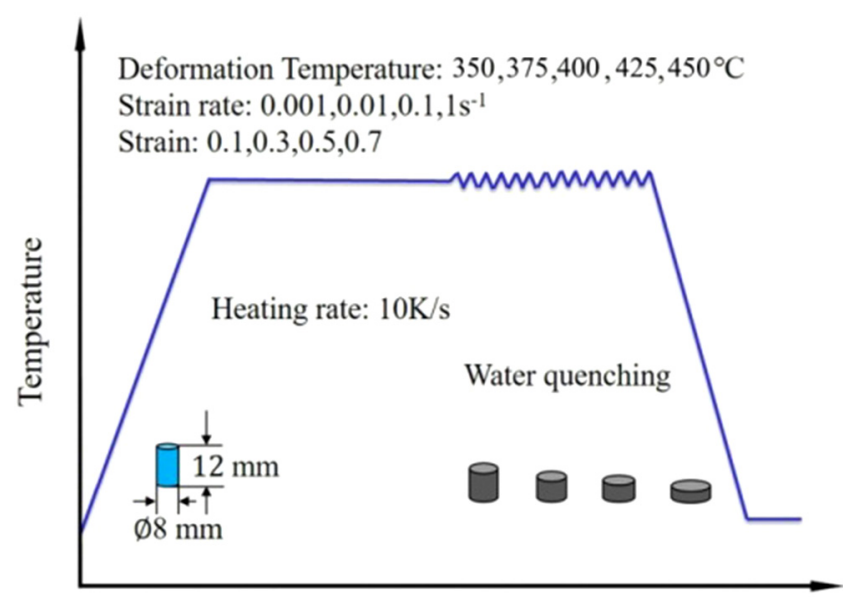

Time

Fig. 1. Experimental procedure for hot compression test.

\section{CA models for dynamic recrystallization}

\subsection{Theoretical model}

\subsubsection{Modelling for dislocation evolution}

The change of dislocation density $\rho$, with strain $\varepsilon$ in the Kocks and Mecking model (K-M model) can be described by $[9]$ :

$$
\frac{d \rho}{d \varepsilon}=k_{1} \sqrt{\rho}-k_{2} \rho
$$

where $k_{1} / k_{2}$ represents the hardening /dynamic softening parameter.

Based on the shear modulus $G$ and the Burgers vector $b$, the flow stress $\sigma$ can be calculated by [9]:

$$
\sigma=\alpha^{\prime} G b \sqrt{\bar{\rho}}
$$

where the value of the interaction factor $\alpha^{\prime}$ is $0.5-1.0$. Based on $N$, the number of the total cells, and $\rho_{i}$, the mean $\rho$ of all cells', $\bar{\rho}$, could be given by:

$$
\bar{\rho}=\frac{1}{N} \sum_{i=1}^{n} \rho_{i}
$$

\subsubsection{Modelling for DRX nucleation and growth}

Based on the strain rate $\dot{\varepsilon}$, temperature $T$ and the universal gas constant $\mathrm{R}$, the dynamic recrystallization nucleation rate could be given by [9]:

$$
\dot{n}(\dot{\varepsilon}, T)=C \dot{\varepsilon}^{m} \exp \left(-\frac{Q_{a c t}}{R T}\right)
$$

where $\mathrm{C}$ represents a constant determined by an inverse analysis method, and $m$ denotes a strain rate sensitive exponent, which is usually set as 1.0 in the CA simulation according to Refs. [11-14]. The deformation activation energy $Q_{\text {act }}$ could be calculated by the result of hot compression experiments [15]. The nucleation rate $\dot{n}$ can be inversely calculated by the following expression [10]:

$$
\eta=\dot{n} \frac{\varepsilon}{\dot{\varepsilon}} \frac{4}{3} \pi r_{d}^{3}
$$

where $r_{\mathrm{d}}$ represents the mean radius of the recrystallized grains, and $\eta$ is the DRX percentage of experimentally result. The critical $\rho$ of DRX during hot deformation could be calculated by [9].

$$
\rho_{c}=\left(\frac{20 \gamma \dot{\varepsilon}}{3 b l M \tau^{2}}\right)^{1 / 3}
$$

where the symbol $\tau$ represents the line energy of dislocation, and symbol $\gamma$ means the energy of grain boundary (GB), see equations (7) [8] and (8) [9]. The dislocation mean free path $l$ and the mobility ratio $M$ of GB was expressed by equations (9)-(11).

$$
\gamma_{i}= \begin{cases}\gamma_{m} & \theta_{i} \geq 15^{\circ} \\ \gamma_{i}=\gamma_{m} \frac{\theta_{i}}{\theta_{m}}\left(1-\ln \left(\frac{\theta_{i}}{\theta_{m}}\right)\right) & \theta_{i}<15^{\circ}\end{cases}
$$

where the $\theta_{\mathrm{i}}$ represents the $i_{\mathrm{th}}$ recrystallized grain misorientation with its neighboring one, and $\theta_{\mathrm{m}}$ means the high angle misorientation (taken as $15^{\circ}$ ).

$$
\gamma_{m}=\frac{G b \theta_{m}}{4 \pi(1-\mu)}
$$

where $\mu$ is the Poisson's ratio.

$$
l=\frac{K_{1} G b}{\sigma}
$$

where the constant $K_{1}$ is usually about 10 for most metals.

$$
M=\frac{\delta D_{o b} b}{K T} \exp \left(\frac{-Q_{b}}{R T}\right)
$$

where $K$ represents Boltzmann's constant. The $\delta, Q_{\mathrm{b}}$ and $D_{\text {ob }}$ are the characteristic grain boundary thickness, diffusion activation energy and diffusion factor, respectively.

\subsubsection{Modelling of DRX growing}

The driving force $\left(\Delta f_{\mathrm{i}}\right)$ depends on the difference of $\rho_{\mathrm{m}}$ and $\rho_{\mathrm{d}}[10]$ :

$$
v_{i}=M \Delta f_{i}
$$

For the assumed spherical recrystallized grains:

$$
\Delta f_{i}=\tau\left(\rho_{m}-\rho_{d}\right)-\frac{2 \gamma}{r_{i}}
$$


where $r_{\mathrm{i}}$ and $\rho_{\mathrm{d}} / \rho_{\mathrm{m}}$ is the radius and $\rho$ of recrystallized grain / matrix, respectively.

Displacement increment $\left(\Delta x_{\mathrm{i}}\right)$ and time increment $(\Delta t)$ could be calculated by equations (13) and (14):

$$
\begin{gathered}
\Delta x_{i}=v_{i} \Delta t \\
\Delta t=\frac{L_{0}}{V_{\max }}=\frac{k_{2}^{2} L_{0}}{M \tau k_{1}^{2}}
\end{gathered}
$$

In this study, the length and width of each cell are both set as the constant $L_{0}$ in the hot compression process, the growth criterion can be written as:

$$
\Delta x_{i}>L_{0}\left(\sqrt{\frac{n_{i}+1}{\pi}}-\sqrt{\frac{n_{i}}{\pi}}\right)
$$

where $n_{\mathrm{i}}$ denotes the number of cells in the $i_{\mathrm{th}}$ DRX grain.

\subsection{Simulation conditions of solution-treated (ST) and as-rolled (AR) alloy}

In this study, the total cell number is 160000 (initial matrix size $400 \times 400)$ in the $\mathrm{CA}$ model, which corresponds to $1000 \mu \mathrm{m} \times 1000 \mu \mathrm{m}$ in a real sample. The length and width $L_{0}$ of each cell is arbitrarily chosen to be $2.5 \mu \mathrm{m}$. Meanwhile, the Neumann's neighboring rule and periodic boundary conditions are applied in this CA simulation.

\subsection{General model for matrix deformation}

\subsubsection{Matrix deformation theory}

In this work, the grain shape is supposed to be spherical, which changes into an ellipsoid during the compression process. The deformation is described by the $2 \times 2$ matrix, thus the homogenous deformation matrix $S$ can convert the vector $u$ into $v$ as follows:

$$
v=S u
$$

Based on the initial vector $\left(u_{i}\right.$ (where, $\left.i=x, y\right)$ ), new vector $\left(v_{i}\right.$ (where, $\left.\left.i=x, y\right)\right)$ and principle nominal deformation in $x$ and $y$ direction $\left(l_{i}(\right.$ where, $\left.i=x, y)\right)$, the matrix can be written as:

$$
\left[\begin{array}{l}
v_{x} \\
v_{y}
\end{array}\right]=\left[\begin{array}{ll}
l_{x} & 0 \\
0 & l_{y}
\end{array}\right]\left[\begin{array}{l}
u_{x} \\
u_{y}
\end{array}\right]
$$

where $l_{\mathrm{i}}$ denotes the ratio of final length to the original length of the unit vector ahead the axes, and $l_{x} l_{y}=1$.

\subsubsection{Matrix deformation model}

The dimensions of initial matrix and deformed matrix are supposed to be $\mathrm{a} \times \mathrm{b}$ and $m \times n$, respectively. Assuming that the area in $2 \mathrm{D}$ model remain constant during deformation, $a \times b=m \times n$. In the MATLAB model, $L C A$ represents the length of each square cell. The initial matrix height is $a \times L C A$, and the deformed matrix height is $m \times L C A$, thus the true strain $\varepsilon t$ and engineering strain $\varepsilon_{e}$ can be described as follows:

$$
\begin{gathered}
\varepsilon_{t}=\left|\ln \frac{m \times L_{C A}}{a \times L_{C A}}\right|=\ln \frac{a}{m} \\
\varepsilon_{e}=\left|\frac{m \times L_{C A}-a \times L_{C A}}{a \times L_{C A}}\right|=\frac{a-m}{a}
\end{gathered}
$$

The relationship between $\varepsilon_{e}$ and $\varepsilon_{t}$ can be obtained by

$$
\varepsilon_{e}=1-\exp \left(-\varepsilon_{t}\right)
$$

Then the rows $m$ of deformed-matrix can be calculated by

$$
m=a \times \exp \left(-\varepsilon_{t}\right)
$$

The columns $n$ of deformed-matrix can be calculated by

$$
n=a \times b / m
$$

\subsubsection{Matrix transformation}

Figure $2 \mathrm{a}$ and $\mathrm{b}$ show the example of geometry change between initial and deformed grain due to matrix deformation in the compression process. It can be seen that there are 20 surrounding neighbors (shown in white dot) of the initial grain (green color), which increases to 22 neighbors after compression deformation, thus the DRX nucleation sites should become more. Therefore, in order to model the DRX process more accurately, the rule of matrix deformation is adopted in this study.

The coordinate of each cell with given orientation value, $O_{\mathrm{ri}}$, in the initial matrix should be transferred to a new one to match the deformed matrix. Meanwhile, the cells in an identical grain are assigned the same orientation value, $O_{\mathrm{ri}}$, to distinguish different grains, which means that the cells with the same $O_{\text {ri }}$ belong to the unique grain, otherwise not. The coordinate transformation could be described in equations (23) and (24):

$$
\begin{gathered}
i=\left\{\begin{array}{cc}
\operatorname{ceil}\left[\frac{i^{\prime}}{1-\varepsilon_{e}}\right], & \operatorname{ceil}\left[\frac{i^{\prime}}{1-\varepsilon_{e}}\right]<a \\
a, & \operatorname{ceil}\left[\frac{i^{\prime}}{1-\varepsilon_{e}}\right] \geq a
\end{array}\right\} \\
j=\left\{\begin{array}{cl}
\operatorname{ceil}\left[j^{\prime} \times\left(1-\varepsilon_{e}\right)\right], & \operatorname{ceil}\left[j^{\prime} \times\left(1-\varepsilon_{e}\right)\right]<b \\
b, & \operatorname{ceil}\left[j^{\prime} \times\left(1-\varepsilon_{e}\right)\right] \geq b
\end{array}\right\}
\end{gathered}
$$

where Ceil $(X)$ is a numerical method to get a smallest integer not less than $X$. The variable $i\left(i^{\prime}\right)$ and $j\left(j^{\prime}\right)$ represent the initial matrix (deformed matrix) $\mathrm{x}$ and y ordinate, respectively. After deformation is finished, the orientation $O_{\mathrm{ri}}(i, j)$ of the cell $S_{i, j}$ in the initial matrix $S(\mathrm{a}, \mathrm{b})$, i.e. matrix $S$ with a rows and b columns, should be transferred to the cell $S_{i}{ }^{\prime}, j$, in the deformed matrix $S^{\prime}(\mathrm{m}, \mathrm{n})$, i.e. matrix $S^{\prime}$ with $m$ rows and $n$ columns. 
(a)
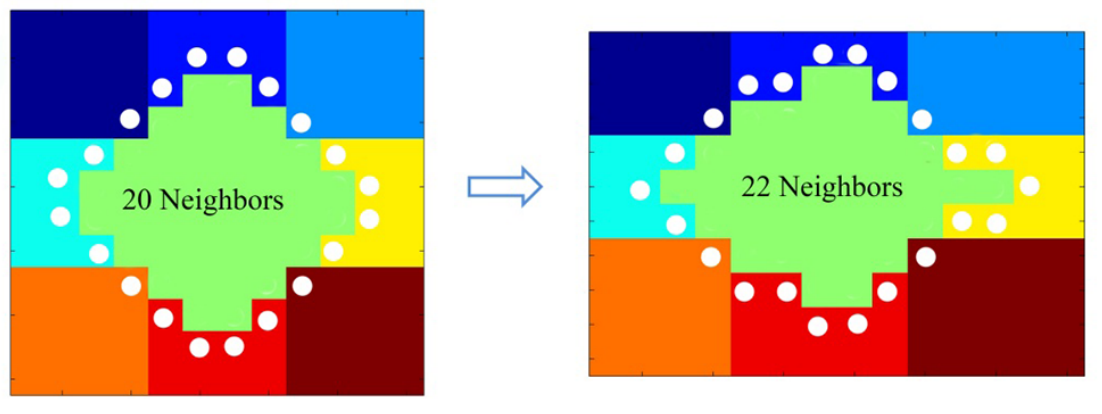

Initial
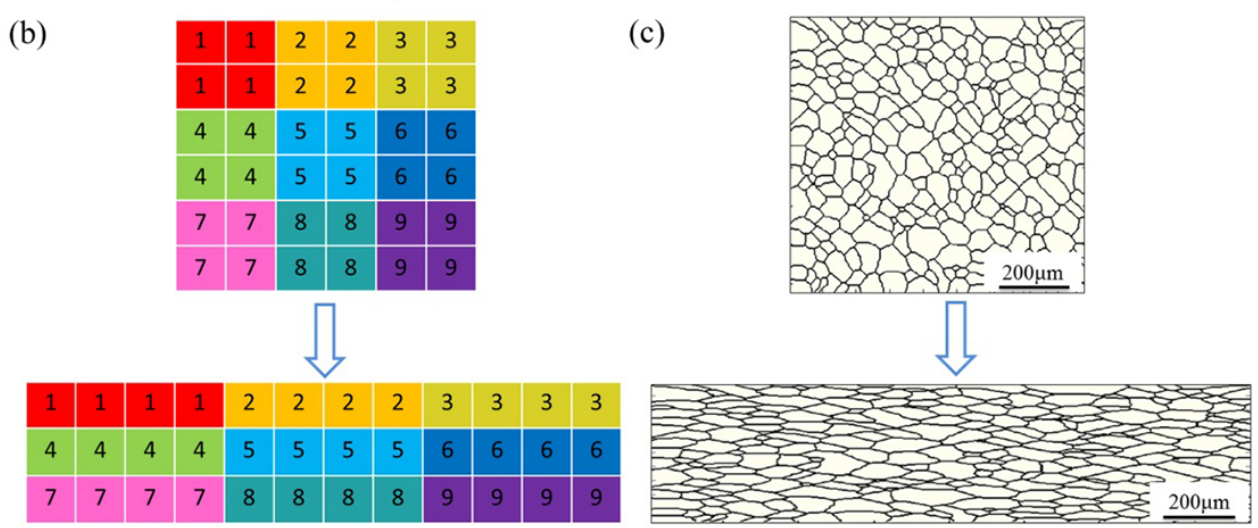

Fig. 2. Schematic diagram of grain topology with matrix deformation: (a) schematic diagram of geometry change due to matrix deformation, (b) schematic diagram of matrix deformation, $\varepsilon_{e}=0.5$, (c) grain topology induced by matrix deformation, $\varepsilon_{e}=0.5$, (initial average grain size $d_{0}=44.5 \mu \mathrm{m}$ ).

Figure 2b show the schematic diagrams of matrix deformation and grain topology under certain strain. There are 9 grains with different $O_{\mathrm{ri}}(1-9)$ and colors in initial matrix, and each grain has four cells with the same $O_{\mathrm{ri}}$, as illustrated in Figure 2b. As the matrix deformation reaches $50 \%$, the initial two-dimensional matrix $S(6,6)$ is changed into a new two-dimensional matrix $S^{\prime}(3,12)$, and thus the geometry of initial matrix will change correspondingly. Meanwhile, the information of each cell in initial matrix is transferred to the corresponding cell in deformed matrix, respectively. For instance, cell $S_{2,5}^{\prime}$ corresponds to $S_{4,3}$ and $S_{2,7}$ corresponds to $S_{4,4}$ according to equations (23) and (24). Figure 2c displays the grains topology caused by matrix deformation with initial average grain size $44.5 \mu \mathrm{m}$, which is close to that in the solution treated AZ61 $\mathrm{Mg}$ alloy in this study.

\section{Results and discussion}

\subsection{Hot compression strain-stress analysis}

Figure 3 presents the experimental results of hot compression with the $T$ of $350-450^{\circ} \mathrm{C}$. As the true strain enhanced, the stress increased dramatically and continuously. Beyond the maximum value, the stress reduced gradually and even to a steady state.

The adaptive activation energy $Q_{a c t}$ under different true strains $\varepsilon$ were incorporated into the $\mathrm{CA}$ model.
The Qact corresponding to $\varepsilon$ varying from 0.05 to 0.7 were calculated with interval of 0.05 . Through linear fitting of $\ln \sinh (\alpha \sigma)-1 / T$ and $\ln \sinh (\alpha \sigma)-\ln \varepsilon$, the activation energy $Q_{\text {act }}$ was calculated as 166 KJ. Based on the linear relationship of $\ln Z-\ln \sinh (\alpha \sigma)$, where $\mathrm{Z}$ is the ZenerHollomon parameter, the stress constant $n$ of as-received AZ61 Mg alloy was calculated to be 8.7, and the correlation coefficient reached 0.908 , which indicates that it was reliable to describe the hot deformation behavior of the $\mathrm{Mg}$ alloy by using hyperbolic sine law [1]. By means of least squares polynomial fitting of the deformation energy under various strains, the evolution of deformation energy $Q_{\text {act }}$ with true strain can be written as:

$$
Q_{a c t}=214-208 \varepsilon+315 \varepsilon^{2}-938 \varepsilon^{3}+1651 \varepsilon^{4}-905 \varepsilon^{5}
$$

\subsection{Microstructural evolution of simulaiton}

Figure 4 exhibits the simulation results of microstructure evolution of AZ61 magnesium alloy under hot deformation $\left(400^{\circ} \mathrm{C}, \dot{\varepsilon}=0.001 \mathrm{~s}^{-1}\right)$.

\subsection{Flow stress prediction using simulation}

Figure 5 compares the peak stress and s one of the AZ61 magnesium alloy. There is little difference between the experimental datum and simulated ones. 

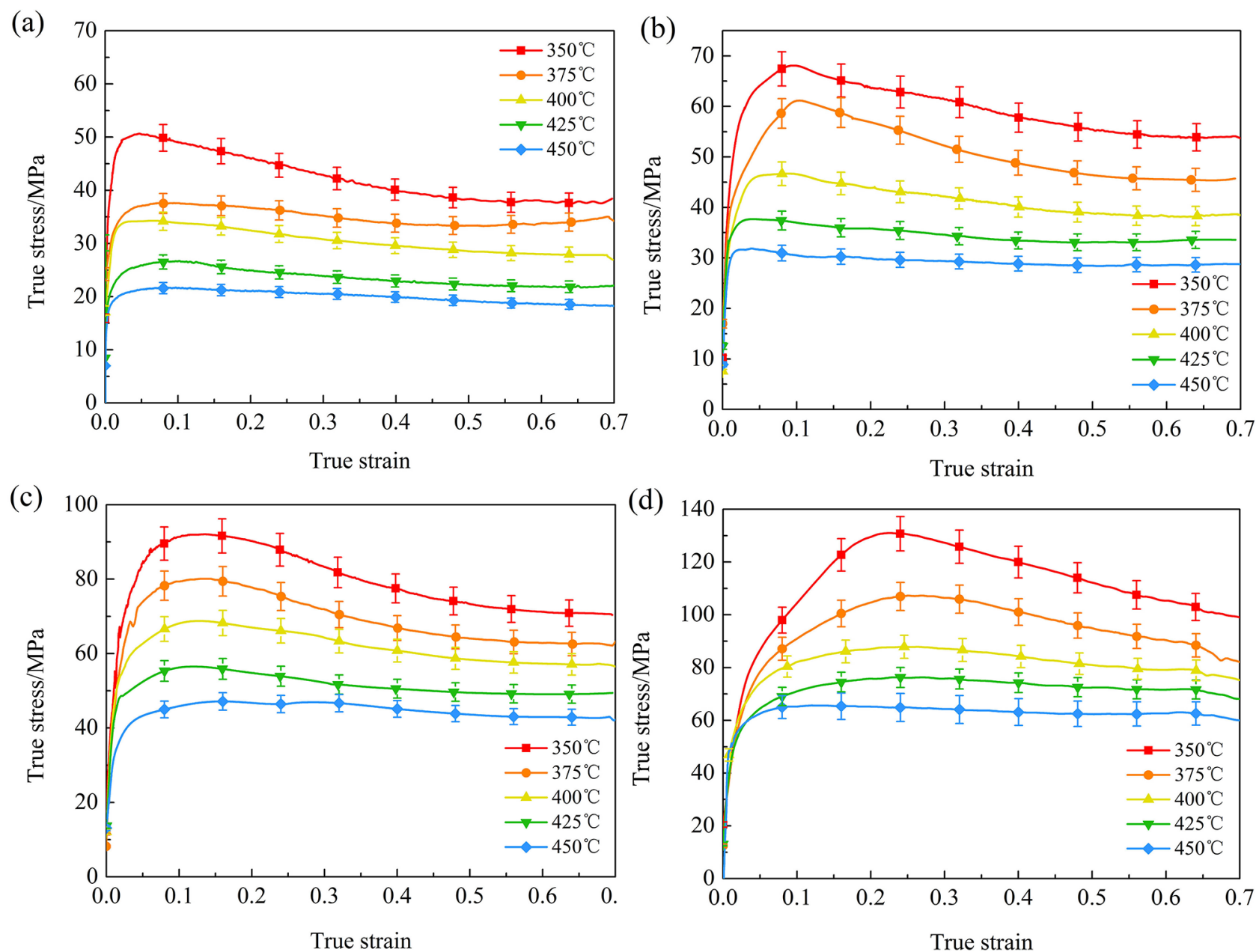

Fig. 3. Hot compression results of AZ61 magnesium alloy: (a) $\dot{\varepsilon}=0.001 \mathrm{~s}^{-1}$; (b) $\dot{\varepsilon}=0.01 \mathrm{~s}^{-1} ;$ (c) $\dot{\varepsilon}=0.1 \mathrm{~s}^{-1} ;(\mathrm{d}) \dot{\varepsilon}=1 \mathrm{~s}^{-1}$.
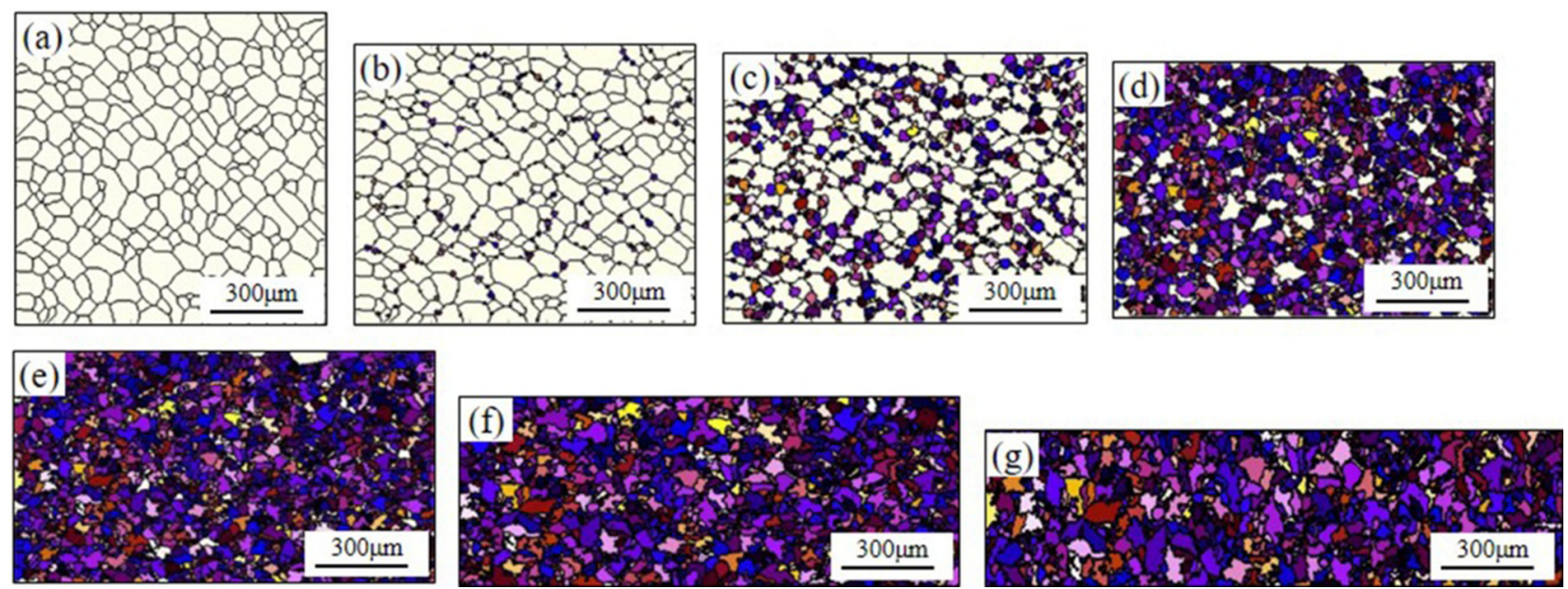

Fig. 4. AZ61 microstructure of simulation result under hot deformation with different $\varepsilon\left(400^{\circ} \mathrm{C}, \dot{\varepsilon}=0.001 \mathrm{~s}^{-1}\right):(\mathrm{a}) \varepsilon_{\mathrm{t}}=0,(\mathrm{~b}) \varepsilon_{\mathrm{t}}=0.1$, (c) $\varepsilon_{\mathrm{t}}=0.15$, (d) $\varepsilon_{\mathrm{t}}=0.2$, (e) $\varepsilon_{\mathrm{t}}=0.3$, (f) $\varepsilon_{\mathrm{t}}=0.5$, (g) $\varepsilon_{\mathrm{t}}=0.7$.

\subsection{Microstructure prediction during hot compression}

Figure 6 presents the simulated and experimental microstructures of hot deformation samples under different $T$.
Table 1 lists the average grain sizes of simulated and experimental results.

Figure 7 presents the variation curves of dynamic recrystallization, including volume fraction and average 

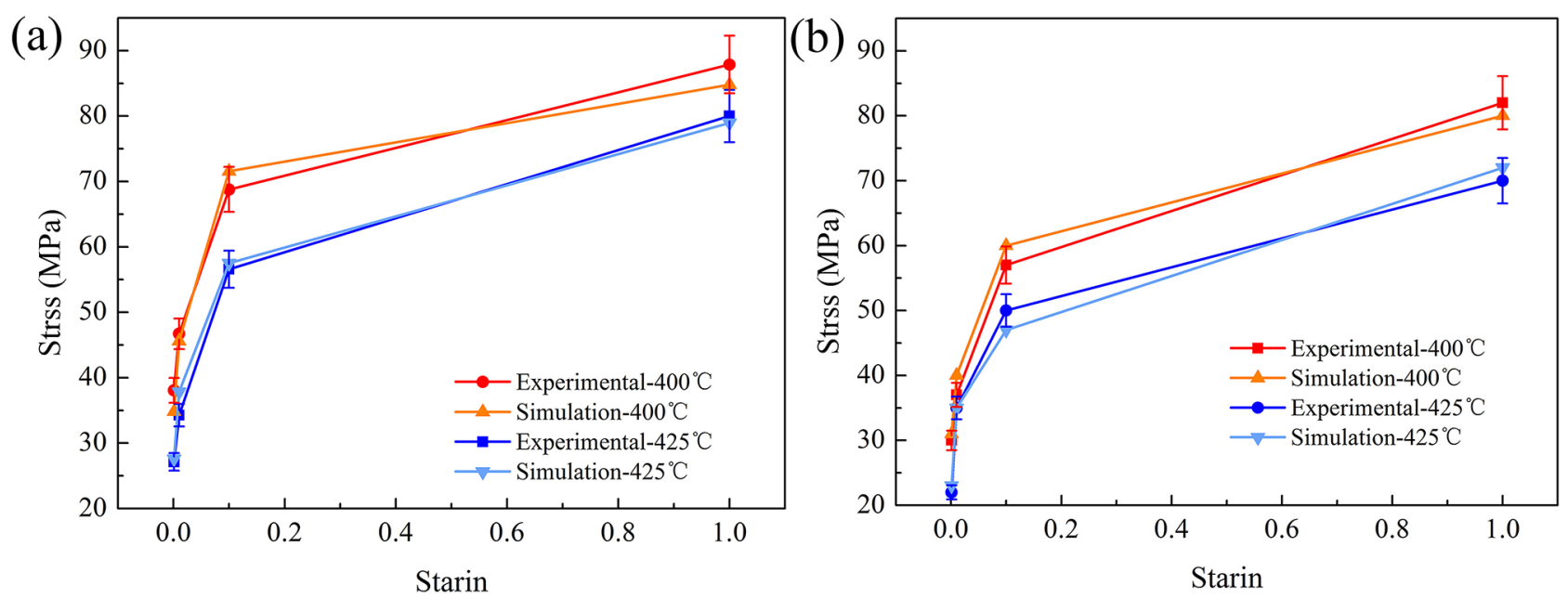

Fig. 5. Comparison between peak stress and steady stress by experimental and simulation of AZ61 magnesium alloy sample $(T=400$ and $425^{\circ} \mathrm{C}, \dot{\varepsilon}=0.001-1 \mathrm{~s}^{-1}$ ): (a) $\sigma_{\mathrm{p}}$-strain, (b) steady stress-strain.

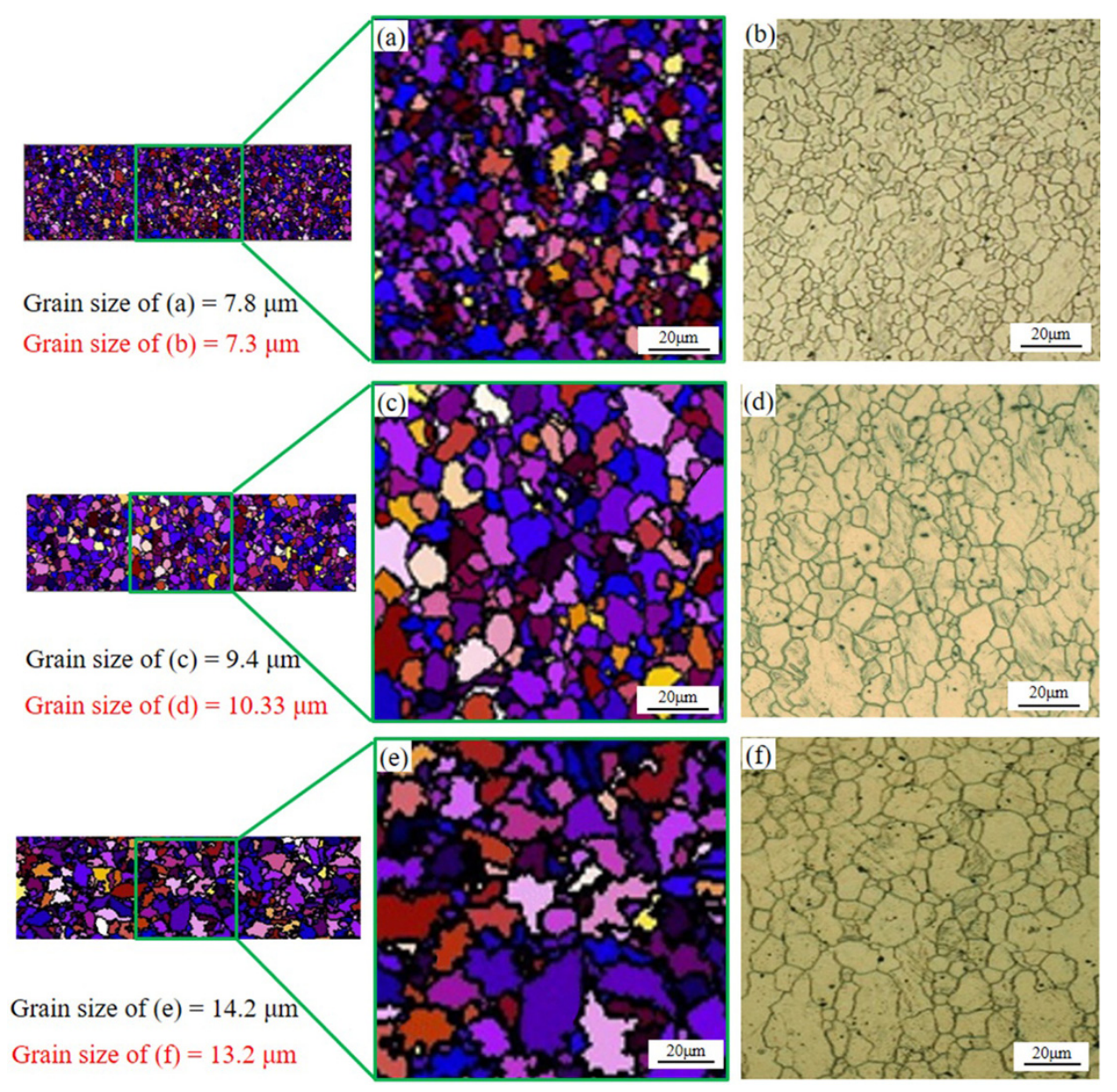

Fig. 6. Microstructures comparison between CA simulation datum and experimental results and different $T\left(\dot{\varepsilon}=0.001 \mathrm{~s}^{-1}, \varepsilon=0.7\right)$ : (a) and (b) $T=350{ }^{\circ} \mathrm{C}$; (c) and (d) $T=400^{\circ} \mathrm{C}$; (e) and (f) $T=450{ }^{\circ} \mathrm{C}$.

grain size. When the strain rate increased, the dislocation pile-up was more serious and the dislocation storage energy became greater, resulting in higher DRX nucleation rate and more recrystallized grains. However, the DRX grains did not have enough time to grow up under high strain rate, thus the grain size was smaller under high strain rate than that under low strain rate when the DRX process was completed. Also, it could be found that the mean grain size 
Table 1. Average grain size of simulation and experimental results under true strain $\varepsilon=0.7$.

\begin{tabular}{lllllll}
\hline$T /\left({ }^{\circ} \mathrm{C}\right)$ & 350 & 350 & 400 & 400 & 450 & 450 \\
$\dot{\varepsilon} /\left(\mathrm{s}^{-1}\right)$ & 0.001 & 0.1 & 0.001 & 0.1 & 0.001 & 0.1 \\
Simulation $(\mu \mathrm{m})$ & 7.8 & 5.0 & 9.4 & 7.77 & 14.2 & 8.7 \\
Experiment $(\mu \mathrm{m})$ & $7.3 \pm 0.4$ & $5.1 \pm 0.2$ & $10.33 \pm 0.5$ & $7.06 \pm 0.3$ & $13.2 \pm 0.6$ & $9.2 \pm 0.3$ \\
Deviation $(\%)$ & 6.8 & 1.9 & 9 & 10 & 7.5 & 5.4 \\
\hline
\end{tabular}

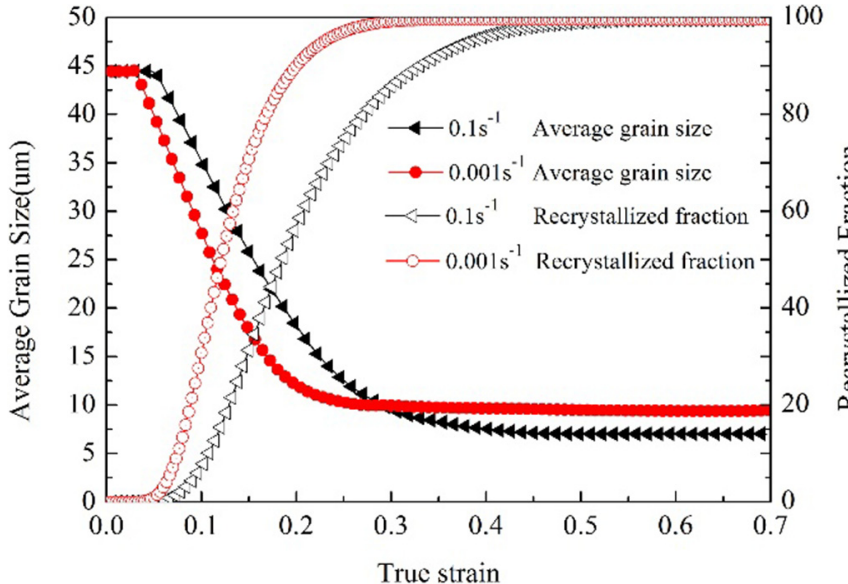

Fig. 7. The relationship between average grain size, strain rate, and recrystallization fraction $\left(T=400^{\circ} \mathrm{C}, \dot{\varepsilon}=0.1 \mathrm{~s}^{-1}\right)$

reduced once the dynamic recrystallization occurred. With the progress of hot compression, the DRX fraction increased gradually. Until the plastic strain reached certain value, the DRX process finished and then the DRX grains ceased to refine.

\section{Conclusions}

The CA model coupled with adaptive deformation energy and matrix deformation topology has been established to simulate the DRX process of AZ61 magnesium alloy in the temperature range of $350 \sim 450{ }^{\circ} \mathrm{C}$ and the strain rate range of $0.001-1 \mathrm{~s}-1$. The simulated peak stress and steady stress values were very close to the experimental ones. The deviation of the average grain size between the simulation and experimental results was less than $10 \%$.

Meanwhile, the simulated DRX process as well as microstructure evolution was in good accordance with the experimental ones from the hot compression of AZ61 Mg alloy, which indicates the reliability of the present $\mathrm{CA}$ model coupled with adaptive activation energy and topology deformation technology.

The CA simulation results indicate that the decrease of strain rate accelerated the DXR process and the mean grain size increased with the decrease of strain rate, which was quite consistent with the experimental results of the hot compression.

\section{Nomenclature}

Dislocation density

True strain

Hardening parameters

Softening parameters

Flow stress

Shear modulus

Burgers vector

Mean dislocation density of all cells

Dislocation density of Number $i$ cell

The number of total cells

Nucleation rate

Constant

Strain rate sensitive exponent, set as 1.0

Deformation activation energy

Universal gas constant, 8.31

Deformation temperature

Strain rate

Material constants

Material constants

Material constants

DRX percentage

Mean radius of recrystallized grains

Critical dislocation density

Grain boundary energy

Dislocation mean free path

Grain boundary mobility ratio

grain boundary misorientation

Grain boundary energy

Grain boundary misorientation between the $i_{\mathrm{th}}$ recrystallized grain and its neighboring grain

$\theta_{\mathrm{m}} \quad$ Grain boundary misorientation in the case of the occurrence of a high angle boundary (taken as $15^{\circ}$ )

$\mu \quad$ Poisson's ratio

$K_{1} \quad$ Constant of 10 for most metals

$\delta \quad$ Characteristic grain boundary thickness

$D_{\text {ob }} \quad$ Boundary self-diffusion coefficient

$K \quad$ Boltzmann's constant

$Q_{\mathrm{b}} \quad$ Activation energy for the boundary diffusion.

$v_{\mathrm{i}} \quad$ Growth velocity

$\Delta f_{\mathrm{i}} \quad$ Driving force for the $i_{\text {th }}$ recrystallized grain

$\rho_{m} \quad$ Dislocation density of the matrix

$\rho_{d} \quad$ Dislocation density of recrystallized grain

$r_{\mathrm{i}} \quad$ The radius of the $i_{\mathrm{th}}$ recrystallized grain 
$\Delta x_{\mathrm{i}} \quad$ Displacement increment of $i_{\text {th }}$ recrystallized grain

$\Delta t \quad$ Time increment

$L_{0} \quad$ Length of each cell

$n_{\mathrm{i}} \quad$ The numbers of cells in the $i_{\mathrm{th}}$ DRX grain

$u_{i}(i=x, y) \quad$ Initial vector of $x$ and $y$ direction

$v_{i}(i=x, y) \quad$ New vector of $x$ and $y$ direction after deformation

$l_{\mathrm{i}}(i=x, y) \quad$ Length in $x, y$ axes of deformed matrix

$\varepsilon_{e} \quad$ Engineering strain

$\varepsilon_{t} \quad$ True strain

$a \times b \quad$ Cell number of row $\times$ column (initial matrix)

$m \times n \quad$ Cell number of row $\times$ column (deformed matrix)

$\operatorname{ceil}(x) \quad$ map a the smallest integer not less than $x$

$\sigma_{\mathrm{p}} \quad$ Peak stress

$\varepsilon_{c} \quad$ Critical strain

$\varepsilon_{p} \quad$ Peak strain

$k \quad$ Material constants

$\theta \quad$ Strain hardening

$\sigma_{\mathrm{ss}} \quad$ Steady-state stress

$X_{\mathrm{DRX}} \quad$ Dynamic recrystallization fraction

This work is supported by the National Natural Science Foundation of China (No. 51775137).

\section{Author contribution}

Wenchen Xu, Writing-Review \& Editing; Sibing Wang, WritingOriginal Draft Preparation, He Wu, Data curation; Ranxu Yuan, software; Xueze Jin, performed the experiments and Data curation; Debin Shan, Supervision.

\section{References}

1. H. Yu, Y. Sun, L. Hu, Z. Wan, H. Zhou, J. Alloys Compd. 704 (2017) 537-544

2. S.-M. Baek, H.J. Kim, H.Y. Jeong, S.-D. Sohn, H.-J. Shin, K.-J. Choi, K.-S. Lee, J.G. Lee, C.D. Yim, B.S. You, H.-Y. Ha, S.S. Park, Corros. Sci. 112 (2016) 44-53

3. O. Hilšer, S. Rusz, P. Szkandera, L. Č́žzek, M. Kraus, J. Džugan, W. Maziarz, Metals 8 (2018) 776

4. C.-C. Zhang, H.-Y. Wang, M. Zha, C. Wang, J.-H. Li, Z.-Z. Yang, Q.-C. Jiang, Materials 11 (2018) 895

5. G. Bajargan, G. Singh, D. Sivakumar, U. Ramamurty, Mater. Sci. Eng. A 579 (2013) 26-34

6. Y. Xu, L. Hu, Y. Sun, J. Alloys Compd. 580 (2013) 262-269

7. G. Kugler, R. Turk, Comput. Mater. Sci. 37 (2006) 284-291

8. Y. Zhang, S. Jiang, Y. Liang, L. Hu, Comput. Mater. Sci. 71 (2013) 124-134

9. R. Ding, Z.X. Guo, Comput. Mater. Sci. 23 (2002) 209-218

10. G. Kugler, R. Turk, Acta Mater. 52 (2004) 4659-4668

11. H.J. McQueen, N.D. Ryan, Mater. Sci. Eng. A 322 (2002) 43-63

12. R. Ding, Z.X. Guo, Acta Mater. 49 (2001) 3163-3175

13. S. Hore, S.K. Das, S. Banerjee, S. Mukherjee, Mater. Sci. Technol. 28 (2012) 711-718

14. P. Peczak, M.J. Luton, Philos. Mag. 70 (1994) 817-849

15. Z. Jin, Z. Cui, Comput. Mater. Sci. 63 (2012) 249-255

Cite this article as: Sibing Wang, Wenchen $\mathrm{Xu}, \mathrm{He} \mathrm{Wu}$, Ranxu Yuan, Xueze Jin, Debin Shan, Simulation of dynamic recrystallization of a magnesium alloy with a cellular automaton method coupled with adaptive activation energy and matrix deformation topology, Manufacturing Rev. 8, 11 (2021) 